\title{
An observational study of aerosol optical properties and their relationships with meteorological parameters over Bangladesh
}

\author{
Md Mainul Islam Mamun ${ }^{1}$, Md Monirul Islam¹, Ahsan Habib Rasel ${ }^{1}$, \\ Mumnunul Keramat \\ ${ }^{I}$ Department of Applied Physics and Electronic Engineering, University of Rajshahi, Rajshahi 6205, \\ Bangladesh
}

\begin{abstract}
Atmospheric aerosol is important element of atmospheric system and became a major uncertainty in global climate simulation. Therefore proper assessment of aerosol is crucial in current climate diagnostic. In this paper the characteristics of aerosol optical depth $(A O D)$, angstrom exponent $(A E)$ and fine mode fraction $(F M F)$ are derived using MODerate resolution Imaging Spectroradiometer (MODIS) remote sensing data over Bangladesh in the last decade. AOD and FMF are increasing across Bangladesh while AE is decreasing. Western part of Bangladesh shows higher AOD along with lower $A E$ and lower FMF. AOD exhibits negative correlations with both $A E$ and FMF. Monthly and seasonal mean variations of $A O D, A E$ and FMF report the highest $A O D$ in pre-monsoon season while highest $A E$ and highest FMF in post-monsoon season. After that the relationships of $A O D$ with meteorological parameters namely rain rate and land surface temperature are analyzed. The rain rate is derived by Tropical Rainfall Measuring Mission (TRMM) remote sensing data over Bangladesh. The results between AOD and meteorological parameters show good relationships. MODIS land surface temperature reveals strong positive correlation with $A O D$ indicating that higher land surface temperature enhances aerosol loading. TRMM rain rate shows negative correlation with AOD referring that higher rain rate weaken aerosol loading and vice versa. However more studies and longer data sets are needed for approving these arguments.
\end{abstract}

Keywords:Aerosol, MODIS, TRMM, AOD, AE, FMF, Meteorological parameters, Bangladesh.

\section{Introduction}

Atmospheric aerosols are suspended liquid or solid particles in atmosphere. It has different physical and chemical properties. Aerosols influence the global climate system in several ways and became a crucial factor in global climate change [8]. Aerosols change the global radiation budget by scattering and absorbing the solar radiation which has a contribution to radiative forcing [2], [23]. Aerosols alter the cloud properties by changing the cloud droplets size, modifying cloud albedo, cloud life time and the precipitation [19], [26]. Various aerosols types have different effects on the sign and magnitude of aerosol radiative forcing [13]. Aerosols also have effective effects on human health and ecosystem processes [24]. The sources of aerosols, their conduction and transformation also their withdrawal varies over different regions [6]. Aerosols are one of the largest uncertainty sources of current climate change simulation, although many aerosol studies are done [7]. Aerosol optical properties such as aerosol optical depth (AOD), angstrom exponent (AE) and fine mode fraction (FMF) are main factors for climate change studies. Aerosols show high spatial-temporal variations; hence monitoring aerosols is a difficult work. Satellite measurements are an excellent way to acquire information about aerosol characteristics [5], [11]. Especially satellite remote sensing such as MODerate resolution Imaging Spectroradiometer (MODIS) is a cost effective way to monitor aerosol optical properties [27]. MODIS provides global aerosol optical information with spatial and temporal resolutions over both land and ocean by Terra and Aqua satellites [14], [25]. MODIS satellite data has been shown to have tremendous efficient for mapping the distribution and properties of aerosols [4]. Aerosol concentrations are regularly increasing especially in Asia due to growing populations, rapid urbanization with consequent land use changes, increasing industrializations and increasing motorized traffic [1]. There are quite sphere of aerosol studies in Bangladesh [16], [17]. Few aerosol studies in Indian subcontinent have reported that aerosols showed high spatial-temporal variations [1], [20]. [16] found maximum AOD during pre-monsoon over Bangladesh and [1] also found highest AOD values during summer seasonsin Pakistan.

In this research MODIS aerosol retrievals are used to analyze the spatial-temporal variability of aerosol optical properties. In addition TRMM rainfall data and MODIS land surface temperature data are used to understand the potential influences of meteorological conditions on aerosols over Bangladesh. 


\subsection{Study Area}

\section{Methodology}

Bangladesh is a developing, densely populated and highly polluted country in South Asia. It has an area of 147,570 squarekm and has 154.7 million populations. It has 1,237.51 persons per square $\mathrm{km}$ the highest population density among large countries and 12th overall. It has the highest border with India in west, north and east (Fig. 1). Also it has some border with Myanmar in southeast and from south the Bay of Bengal is started. Geographically Bangladesh is one of the major parts of the large and fertile Indo-Gangetic plain. The diverse physical environment of Bangladesh has impacts on land use patterns. It has a flat topography. Bangladesh is the largest delta in the world which made by Ganges, Brahmaputra and Meghna river system. The main climatic characteristics of Bangladesh are high temperatures, excessive humidity and fairly marked seasonal variations of precipitation. Distinct seasons are considered in the study area from climatic point of view: (1) the dry winter season from December to February, (2) the pre-monsoon hot summer season from March to May (3) the monsoon or rainy season from June to September and (4) the post-monsoon season which lasts from October to November [21]. The average temperature of the country is $25^{\circ} \mathrm{C}$. The hottest part of the year is March to June characterized by high temperatures as $40^{\circ} \mathrm{C}$ maximum in the west, highest rate of evaporation, and precarious but heavy rainfall. The coolest part of the year is November to March with temperatures range from $8^{\circ} \mathrm{C}$ to $15^{\circ} \mathrm{C}$. Heavy rainfall is the characteristics of Bangladesh and about $80 \%$ of total rainfall occurs during rainy season. The highest rainfall is found in eastern part especially in Sylhet while lowest in western Rajshahi region. During June maximum rainfall is obtained in most places. Fog and mist are very common phenomenon during November to March.

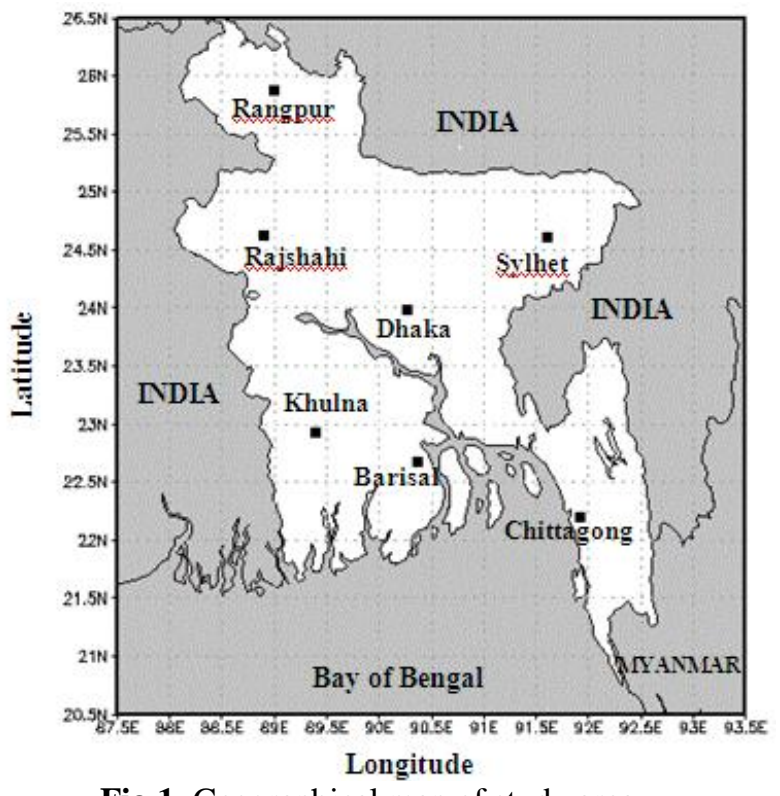

2.2. Data

Fig 1. Geographical map of study area.

\subsubsection{MODerate resolution Imaging Spectroradiometer (MODIS)}

MODIS sensor onboard NASA's Terra and Aqua satellites which providing information of atmosphere, land and oceanic conditions. It has 36 spectral channels. MODIS aerosol products are very useful for details studies of aerosol distributions on local, regional, global and temporal scale. Several aerosol parameters are retrieved at a 10km spatial resolution from MODIS daytime data and have a high accuracy [3], [14], [15], [22]. The data analysis in this paper is derived from MODIS Terra satellite with level 3 aerosol products. AOD, AE and FMF data are used for the period 2004 to 2013. MODIS land surface temperature data products also used to analyze the meteorological conditions over Bangladesh.

\subsubsection{Tropical Rainfall Measuring Mission (TRMM)}

The Tropical Rainfall Measuring Mission (TRMM) is a joint US-Japan program to measure tropical and subtropical rainfall. It uses Precipitation Radar (PR), TRMM Microwave Imager (TMI), and the Visible and Infrared Scanner (VIRS) instruments [10]. TRMM was launched in 1997. It covers the diurnal cycle and two thirds of global rainfall occurs in these tropical to subtropical areas. It initially carried five rain-measuring instruments. [9] used TRMM in determining the climatic characteristics of rainfall over Bangladesh and validated the TRMM rainfall data. Monthly TRMM 3B43 version 7 rain rate data has used in this study with $0.25^{\circ} \times 0.25^{\circ}$ output grid. 


\section{Result And Discussion}

\subsection{Spatial and Temporal Variations of AOD, AE and FMF}

The spatial distributions of AOD, AE and FMF in Bangladesh over the period for 10 years from 2004 to 2013 are presented in Fig. 2. It can be seen that higher AOD with lower AE and lower FMF are observed in a large region at the western part of Bangladesh while smaller AOD with higher AE and higher FMF can be found over the mountainous region of Sylhet and Chittagong the eastern part of Bangladesh. The lowest FMF is noticed in southern part especially in Khulna and Barisal divisions also some areas of Dhaka (Fig. 2c). We can find that AOD, AE and FMF are obviously influenced by topography. With terrain elevation increasing big particle aerosol is gradually cleared by gravitational settling and small particle aerosol is dominant which causes lower AOD and higher angstrom exponent over the mountainous region. Whereas AOD is higher and angstrom exponent is lower over the plain region compared with the mountainous region due to complex aerosol sources, including dust, biomass burning, industry emissions and traffic [28].
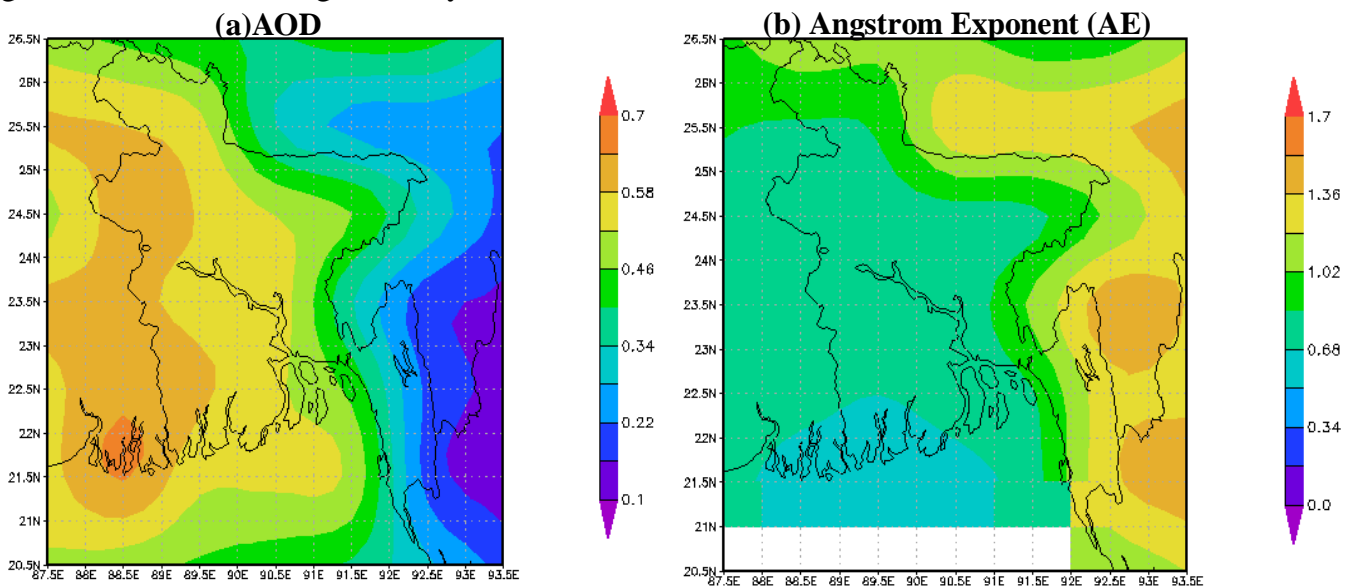

(c) Fine Mode Fraction (FMF)
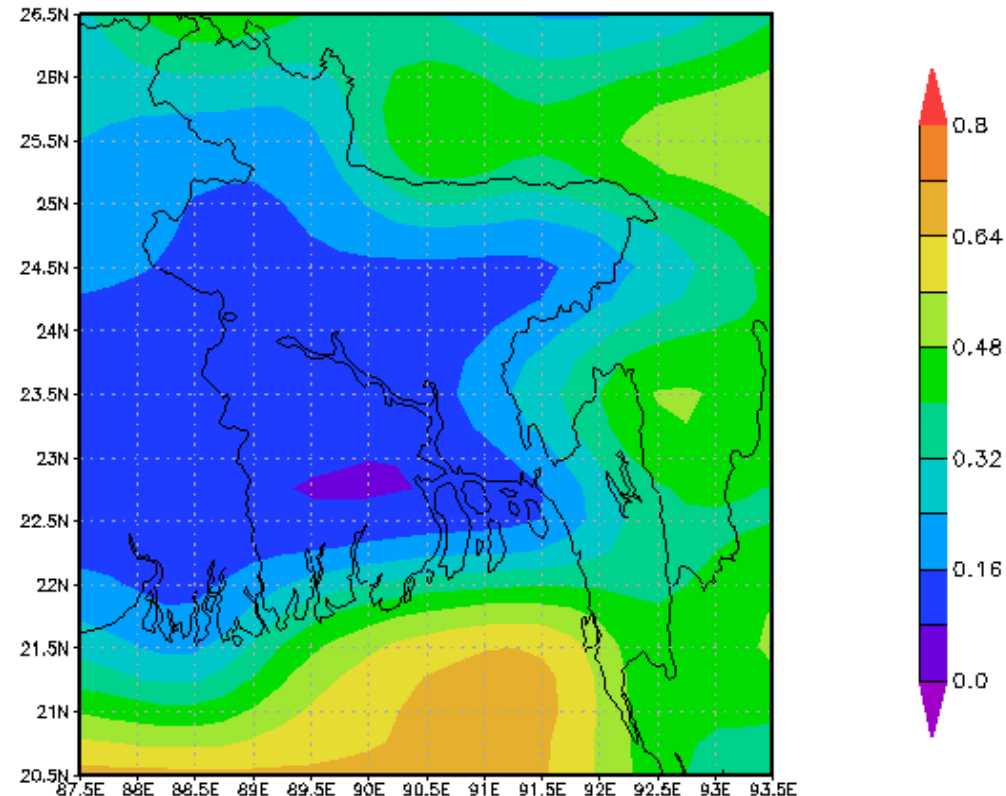

Fig 2. Spatial distributions of annual mean (a) AOD, (b) AE and (c) FMF over Bangladesh for the period 20042013. 


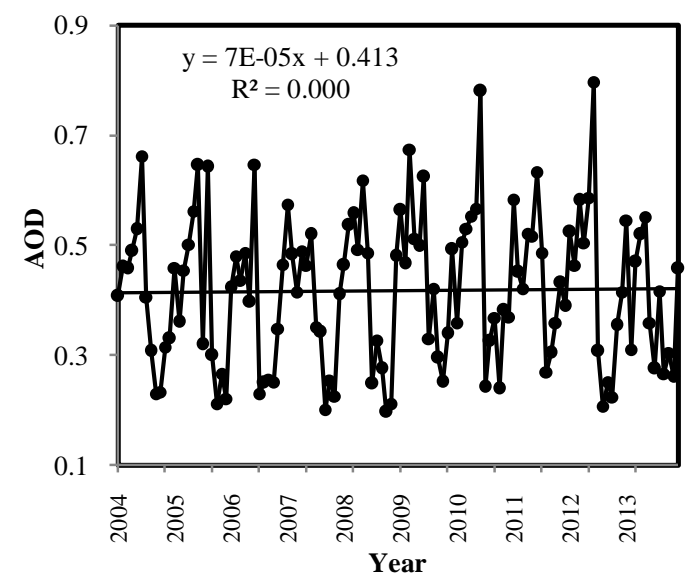

(a)

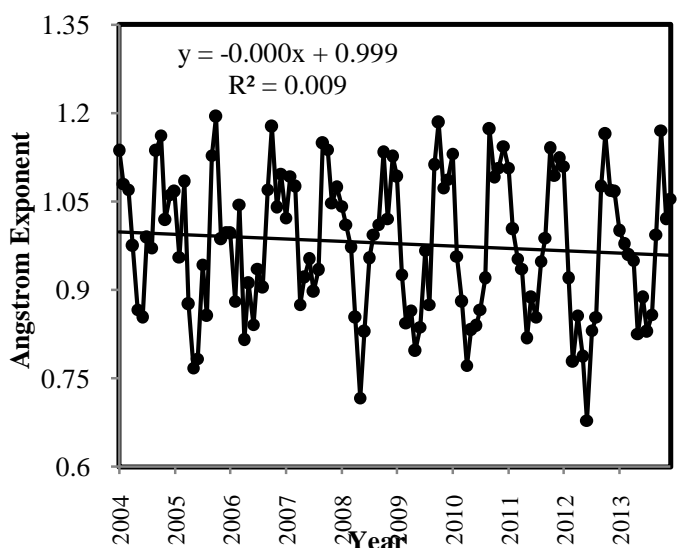

(b)

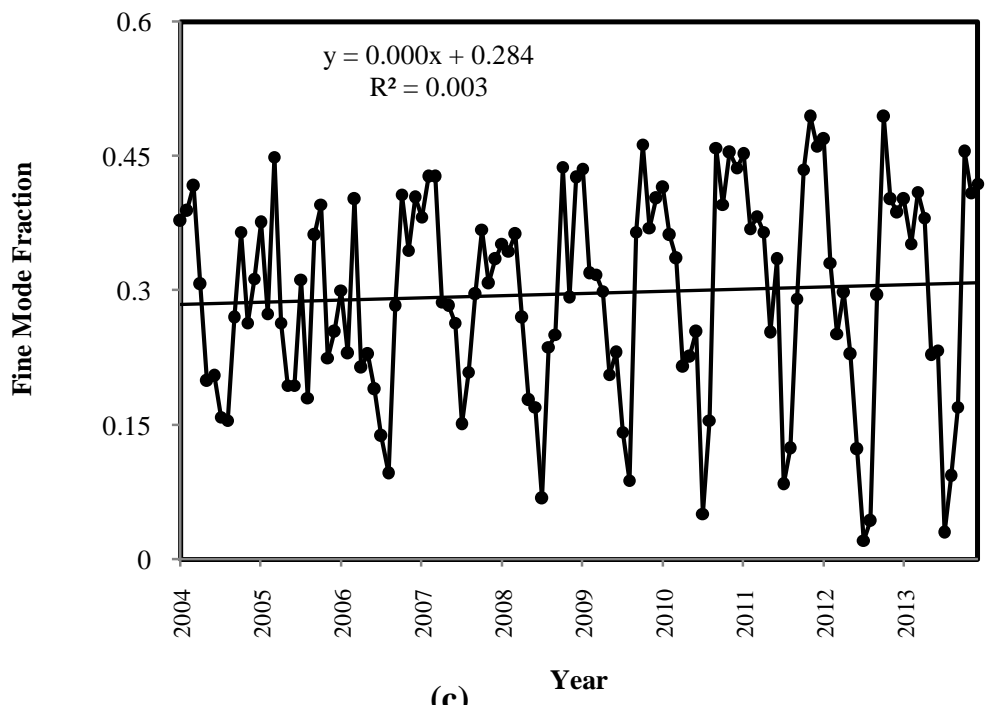

(c)

Fig 3. Area averaged time series and trends of (a) AOD, (b) AE and (c) FMF over Bangladesh during the period 2004-2013.

Table 1 Annual mean AOD, AE and FMF over Bangladesh.

\begin{tabular}{|l|l|l|l|}
\hline Year & AOD & AE & FMF \\
\hline 2004 & 0.40 & 1.03 & 0.29 \\
\hline 2005 & 0.41 & 0.97 & 0.29 \\
\hline 2006 & 0.39 & 0.98 & 0.27 \\
\hline 2007 & 0.40 & 1.02 & 0.31 \\
\hline 2008 & 0.40 & 0.98 & 0.28 \\
\hline 2009 & 0.46 & 0.98 & 0.30 \\
\hline 2010 & 0.44 & 0.98 & 0.31 \\
\hline 2011 & 0.45 & 0.99 & 0.34 \\
\hline 2012 & 0.44 & 0.93 & 0.28 \\
\hline 2013 & 0.40 & 0.96 & 0.30 \\
\hline Average & $\mathbf{0 . 4 2}$ & $\mathbf{0 . 9 8}$ & $\mathbf{0 . 3 0}$ \\
\hline
\end{tabular}

The area averaged time series and trends in AOD, AE and FMF over Bangladesh during 2004 to 2013 are shown in Fig. 3. It could be seen that AOD and FMF are showing increasing trends, indicating an increase in fine mode (small mode) aerosol loading over land areas, which are majorly produced over land mass due to anthropogenic activities; while AE is showing a decreasing trend, indicating the increase in particles with higher diameter, rather than smaller particles. The annual mean AOD, AE and FMF for Bangladesh are 0.42, 0.98 and 0.30 respectively over this period; ranging from 0.39 in 2006 to 0.46 in 2009, from 0.93 in 2012 to 1.03 in 2004 , and from 0.27 in 2006 to 0.34 in 2011 respectively for AOD, AE and FMF (Table 1). Maximum values of AOD, AE and FMF are appeared respectively in 2009, 2004 and 2011, whereas minimum values are in 2006, 2012 and 2006. The highest peak of AOD is appeared in 2012 and the lowest peak is in 2008, also another higher peak appeared in 2010. But AE and FMF temporal variations are presented the similar association. The highest peak 
of AE is in 2005 where the highest peak of FMF is in 2012. On the other hand the lowest AE and FMF both peaks are in 2012.

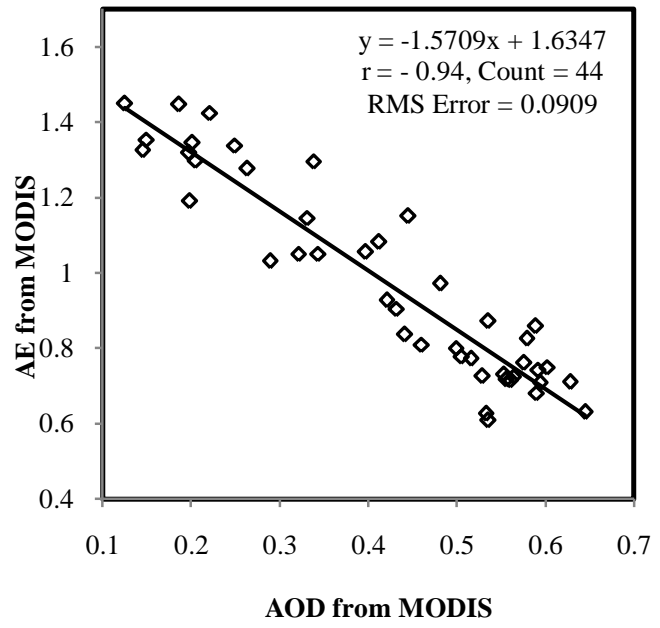

(a)

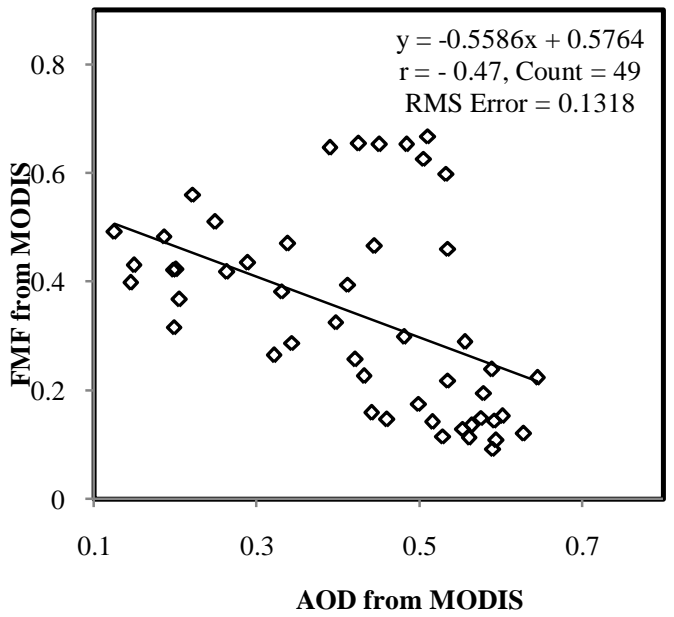

(b)

Fig 4. The scatter plots of AOD vs. (a) AE and (b) FMF over Bangladesh during the period 2004-2013.
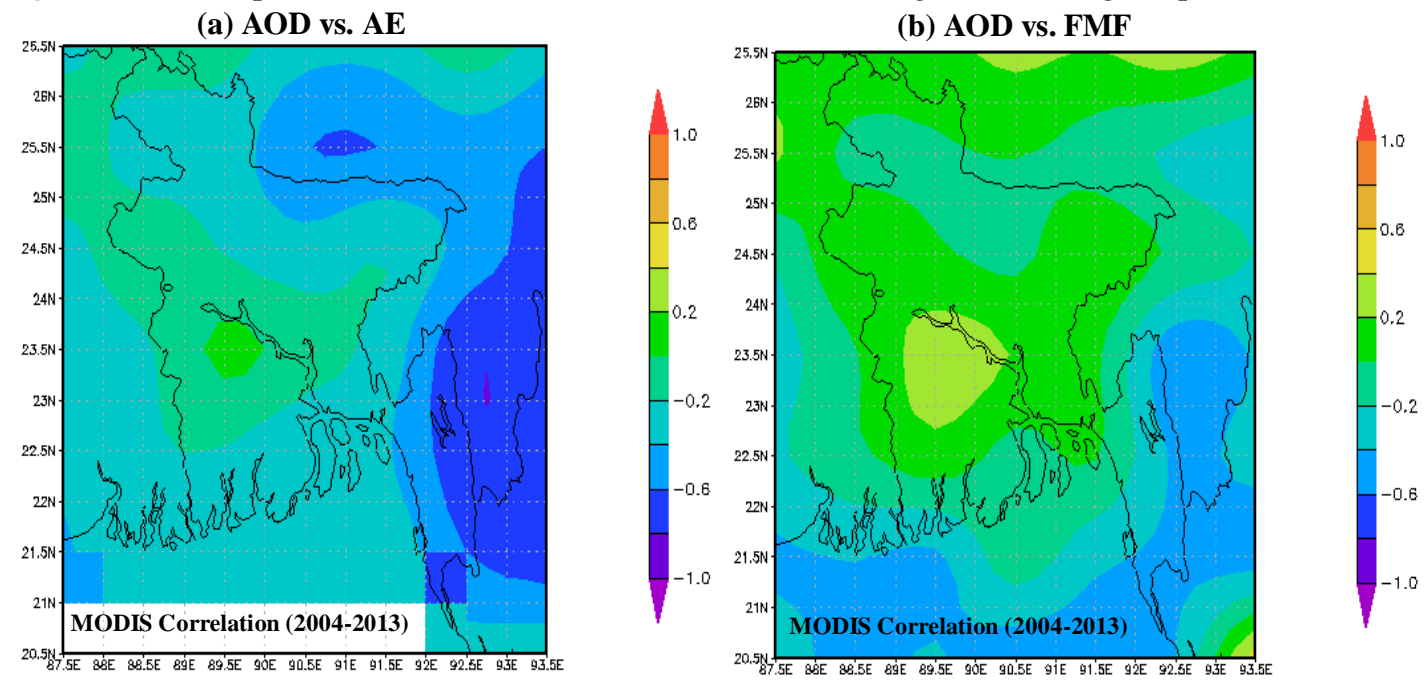

Fig 5. Spatial correlation for AOD vs. (a) AE and (b) FMFover Bangladesh for the period 2004-2013.

\subsection{Correlation of AOD with AE and FMF}

This section deals with the relationships of AOD with AE and FMF over Bangladesh through the use of scatter plots and spatial correlation maps. We used the MODIS data on a monthly basis for the period 2004 to 2013. Fig. 4 presents scattering plots of time averaged AOD from MODIS versus (a) AE and (b) FMF over Bangladesh for the period 2004 to 2013. AE shows a strong negative correlation with AOD. The correlation coefficient is -0.94 and RMS is 0.09 . FMF also shows negative correlation with AOD where the correlation coefficient is -0.47 and RMS is 0.13 . The results suggest that lower AE and FMF increase aerosol loading over Bangladesh and vice versa. Spatial correlation of AOD with AE and FMF are shown in Fig. 5. Spatial correlation between AOD and AE reveals the highest negative correlations are found in Chittagong and Sylhet divisions, but a small positive correlation is observed in Faridpur of Khulna division the adjacent areas of Padma and Jamuna estuaries (Fig. 5a). Spatial correlation between AOD and FMF experiences the higher level of negative correlation in northern and southern part especially the Chittagong division, whereas center of Bangladesh along west to east shown a slight positive correlations. The same area in Faridpur where AE and AOD show positive correlation also shows a higher positive correlation between AOD and FMF with an extended area.

\subsection{Monthly Mean Variations of AOD, FMF and AE}

Monthly variations in AOD, AE and FMF are analyzed using MODIS data over Bangladesh as shown in Fig. 6 and Table 2. The monthly mean AOD, AE and FMF are obtained by averaging all the AOD, AE and 
FMF in the same month during the years 2004 to 2013. The analysis shows that maximum mean AOD, AE and FMF are came into sight respectively in June, October and October, whereas minimum mean values are in October, May and July (Table 2 and Fig. 6). June is the month of the highest AOD and the beginning month of rainy season; in which AOD generally decreased by wet deposition with rainfall increasing (Fig. 6). Table 2 shows a large increase (17\%) in AOD value from 0.53 in May to 0.62 in June and a prominent decrease (48\%) in AOD value from June (0.62) to July (0.32). The great change of AOD should be correlated with an additional aerosol source in June compared to May and July. AE and FMF are exhibited the opposite monthly variations with AOD. At the beginning of the summer AE and FMF start to decrease and reach minimum in May and July respectively and then rapidly increase to their maximum values in October; whereas at the beginning of the summer month March AOD starts to increase and reaches a maximum in June, then rapidly decrease to its minimum value in October. The larger AE values are associated with the presence of small particles and vice versa; whereas decrease FMF indicating reduction in fine or small mode aerosols and vice versa. Therefore AOD is varied with proportion to particles size, AOD increased with increasing in particle size and AOD decreased with decreasing in particle size.

Table 2 Monthly mean AOD, AE and FMF for the year 2004-2013.

\begin{tabular}{lllllllllllll}
\hline & Jan & Feb & Mar & Apr & May & Jun & Jul & Aug & Sep & Oct & Nov & Dec \\
\hline AOD & 0.49 & 0.45 & 0.50 & 0.51 & 0.53 & 0.62 & 0.32 & 0.35 & 0.27 & 0.25 & 0.31 & 0.40 \\
AE & 1.07 & 0.98 & 0.97 & 0.88 & 0.83 & 0.84 & 0.91 & 0.91 & 1.08 & 1.16 & 1.05 & 1.08 \\
FMF & 0.40 & 0.34 & 0.38 & 0.29 & 0.22 & 0.22 & 0.12 & 0.14 & 0.30 & 0.42 & 0.36 & 0.38 \\
\hline
\end{tabular}

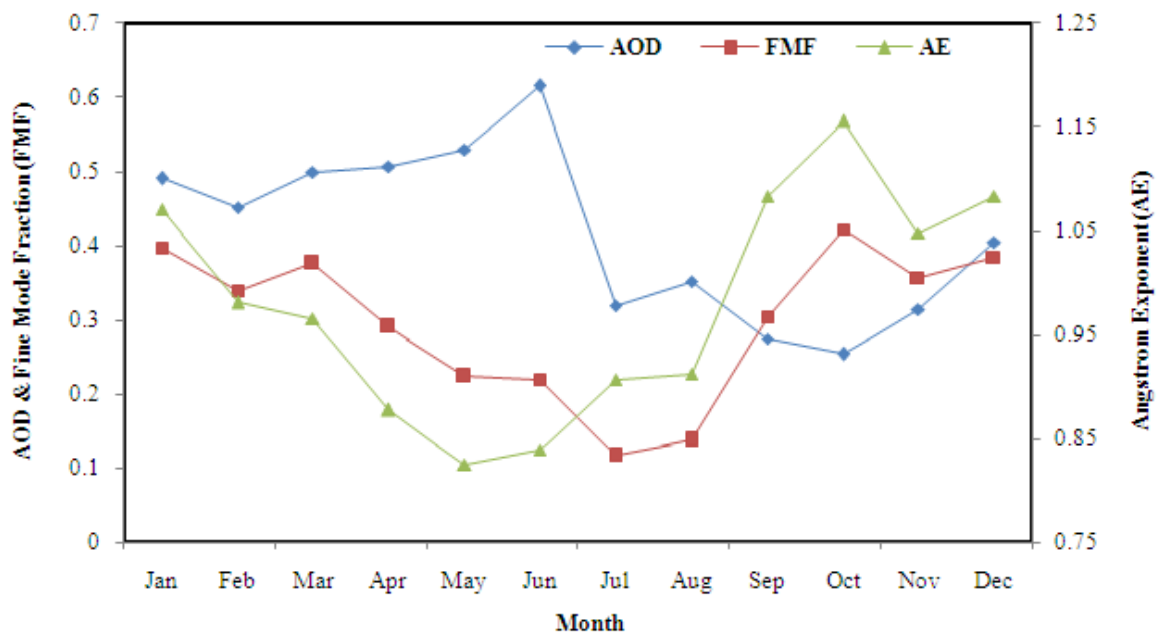

Fig 6. Monthlymean variations of $\mathrm{AOD}, \mathrm{AE}$ and FMF over Bangladesh. The monthly mean $\mathrm{AOD}, \mathrm{AE}$ and FMF are obtained by averaging all the AOD, AE and FMF in the same month during the years 2004-2013.

\subsection{Seasonal Variations of Aerosol Optical Parameters}

\subsubsection{Seasonal Climatological Variations of AOD, AE and FMF}

Monthly data sets of aerosol optical parameters (AOD, AE and FMF) are averaged to make climatology for each season viz. pre-monsoon (March-May), monsoon (June-September), post-monsoon (October-November) and winter (December-February) during each year. Seasonal mean values obtained in each year were averaged in corresponding seasons from 2004 to 2013 to make decadal climatological values over Bangladesh. The climatological mean values of AOD, AE and FMF are shown in Fig.7. The AOD values found to be highest (0.51) during pre-monsoon season over Bangladesh, which may be associated with the influx of sea salt aerosols and aerosols from neighboring country India due to increase wind velocities at this season. The enhanced local land heating due to excessive solar radiation leading to strong transmission, resulting in upwelling of surface particles could be another reason for increased AOD values during pre-monsoon. Despite of high solar radiation the reduction in AOD during monsoon season compared to pre-monsoon could be correlated with rainout and washout of aerosols during monsoon season and associated rainfall, which continue during June-July months [12], [16]. The AOD found to be further lower (0.28) in post-monsoon season. After that a building up of AOD is observed during winter, which increases and reaches maximum during premonsoon. $\mathrm{AE}$, indicating the size of aerosols obtained to be highest during post-monsoon, indicating the abundance of small mode particles. It shows a decreasing values in winter and reaching minimum during premonsoon. Then an increased $\mathrm{AE}$ is observed in monsoon which increased further to post-monsoon. FMF, indicating the presence of finer mode aerosols also found to having highest values during post-monsoon. Its 
value found to be decreasing during winter and reaching minimum during monsoon. After that a building up of FMF is observed in post-monsoon again.

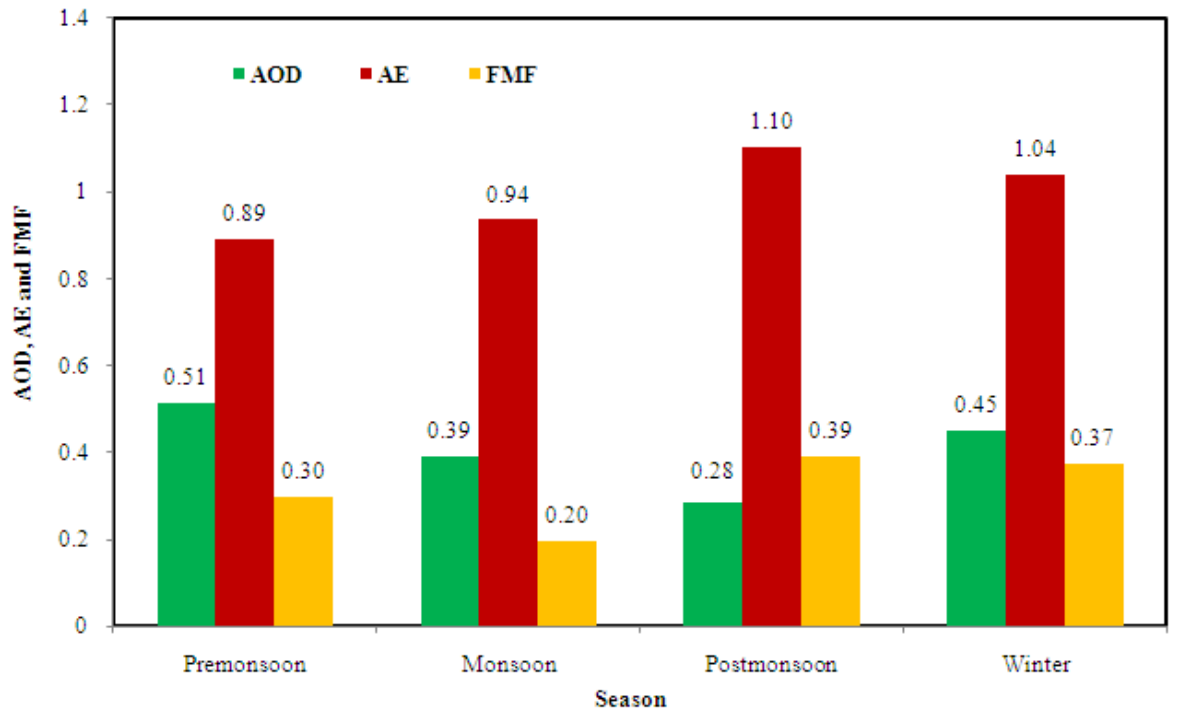

Fig 7.Seasonal mean of (a) AOD, (b) AE and (c) FMF over Bangladesh for the period 2004-2013.

\subsubsection{Seasonal Climatological Trends of Aerosol Optical Properties}

To find the climatological trends in aerosol optical properties during different seasons, linear trend analysis has been performed in seasonal mean values over different seasons during 2004 to 2013 periods over Bangladesh (Fig. 8). It shows a decreasing trend in AOD during monsoon but increasing trends in all other seasons namely pre-monsoon, post-monsoon and winter (Fig. 8a). The observed trend of decreasing in AOD during monsoon indicates that the rainy season pattern may be changing and the monsoonal rainfall may be increasing during the last decade. The increased in AOD trends during pre-monsoon, post-monsoon and winter may be associated with enhancement in transported sea salts during this period from adjacent oceans and increased dust aerosol transport from adjoining deserts of India. AE shows decreasing trends during all the seasons during the last decade indicating increase in aerosol sizes (Fig. 8b). FMF shows increasing trends except in monsoon seasons indicating increase in small or fine mode aerosols during the last decade (Fig. 8c). Decreasing AE and increasing FMF pointing out the increase in aerosol production over land areas due to anthropogenic activities. Decreasing in FMF during monsoon may be the reason of decreased in AOD during the monsoon season over Bangladesh at the last decade.

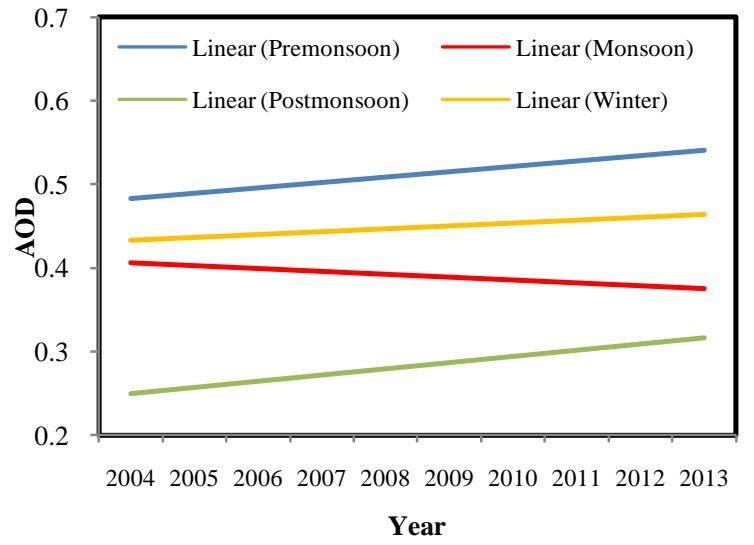

(a)

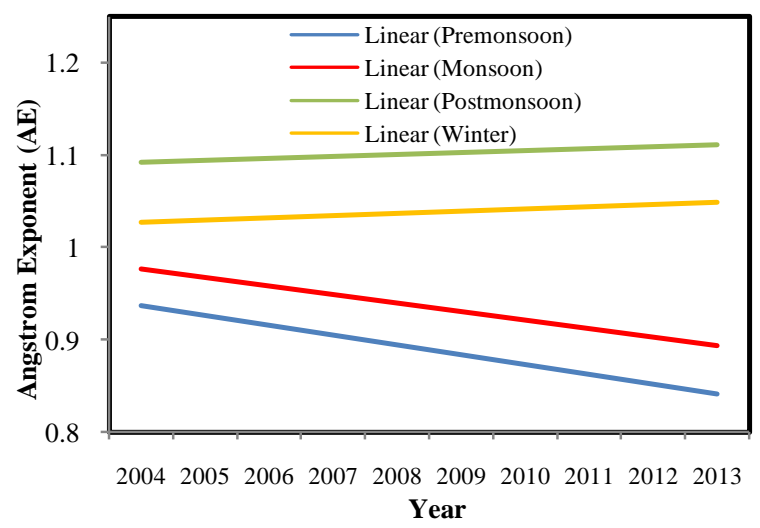

(b) 


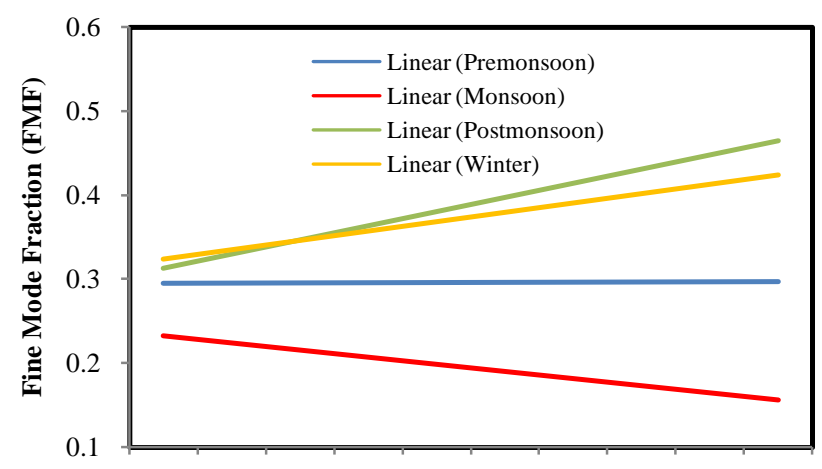

2004200520062007200820092010201120122013

Year

(c)

Fig 8.Seasonal trends of (a) AOD, (b) AE and (c) FMF over Bangladesh. The seasonal mean AOD, AE and FMF are obtained by averaging all the AOD, AE and FMF in the same season during the years 2004-2013.

\subsection{Correlations to Meteorological Parameters}

In this section, the relationship between aerosol and meteorological conditions is discussed. Variations of aerosol depend on various meteorological conditions such as rainfall, temperature, relative humidity etc. Meteorological conditions can affect aerosol by changing its composition and transmission path. Two important meteorological parameters namely rain rate and land surface temperature are analyzed to understand their influence on aerosols. The annual mean spatial distribution and decadal trend of TRMM rain rate is shown in Figs. 9a and 10a respectively. During the last decade rain rate is decreasing in Bangladesh (Fig. 10a). It can be seen that the rain rate is minimum in western parts of Bangladesh (Fig. 9a), the same regions where AOD is revealed maximum values (as shown in Fig. 2a). Also the maximum rain rate and the minimum AOD are observed in Sylhet and Chittagong. This result suggests that AOD and rainfall have a responsible correlation between them. The high rates of rain decrease the airborne particles by washing them out and hence reduce the AODs to its minimum. Conversely the higher AOD because of fewer particles wash out by lower rainfall. Thus the role of rain rate is important for the AOD variation in that region. The annual mean spatial distribution and decadal trend of MODIS land surface temperature during the last decade is given in Figs. $9 \mathrm{~b}$ and $10 \mathrm{~b}$ respectively. Decadal land surface temperature trend is increasing over Bangladesh. The spatial distribution image displays that the maximum land surface temperature is observed in the western part of Bangladesh. AOD and MODIS land surface temperature both are revealed good similarities in variations. Both AOD and land surface temperature are increasing during the decade across Bangladesh. Higher land surface temperature in conjunction with higher AOD is reported in western part while lower values of them are reported in eastern part. Increased AOD over Bangladesh and higher values of AOD in western part of Bangladesh are suggesting that the rise in temperature facilitates additional input of soil derived dust particles into the atmosphere [18].

The correlation of AOD with rain rate and land surface temperature is also analyzed by scattering plots of AOD versus (a) TRMM rain rate and (b) MODIS land surface temperature as shown in Fig. 11. AOD shows a negative correlation with rain rate. The correlation coefficient is -0.37 with a slope of -0.20 (Fig. 11a). While AOD shows a strong positive correlation with land surface temperature. The correlation coefficient between AOD and land surface temperature is 0.73 , RMS is 1.17 (Fig. 11b). These analyses suggest that rainfall and land surface temperature are influenced aerosols and important responsible components for aerosol variability.

(a)TRMM Rain Rate $(\mathbf{m m} / \mathbf{h r})$

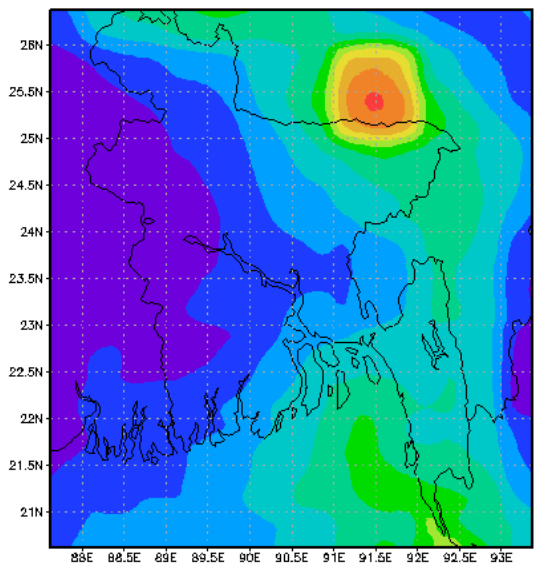

\section{(b) MODIS Land Surface Temperature (K)}

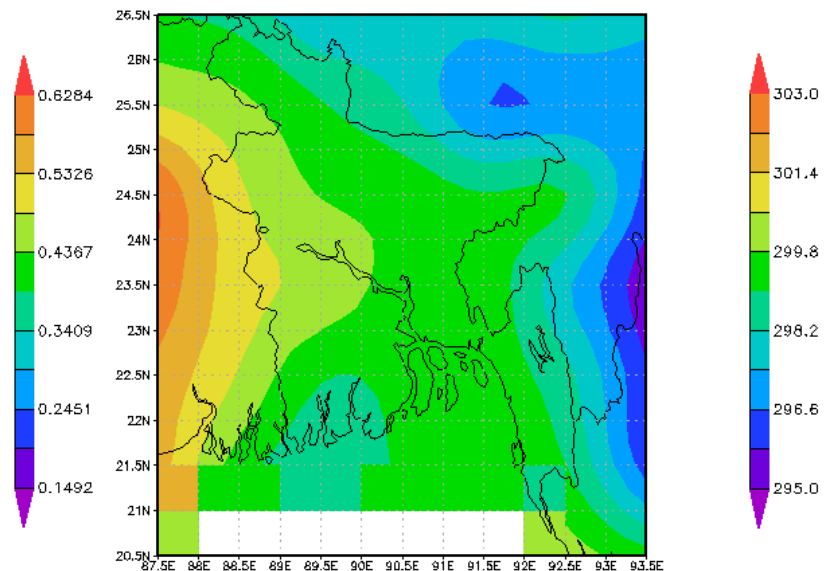

Fig 9.Spatial distributions of annual mean (a) TRMM rain rate (2004-13) and (b) MODIS land surface temperature (2004-2012) over Bangladesh. 


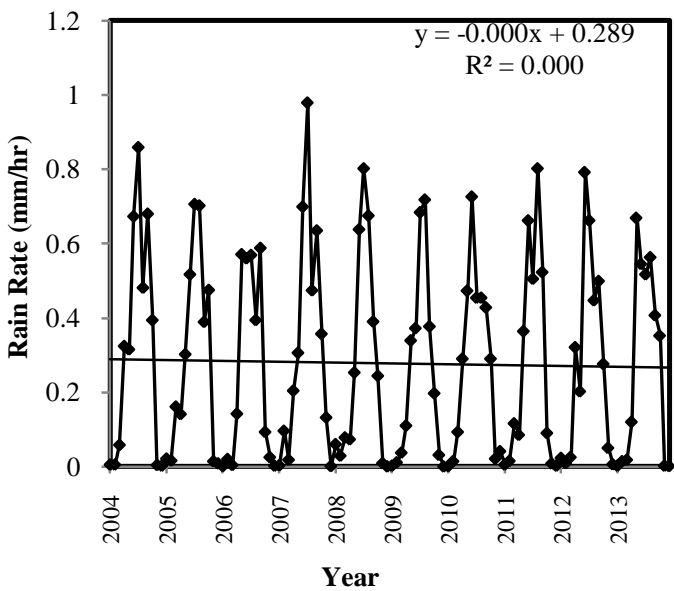

(a)

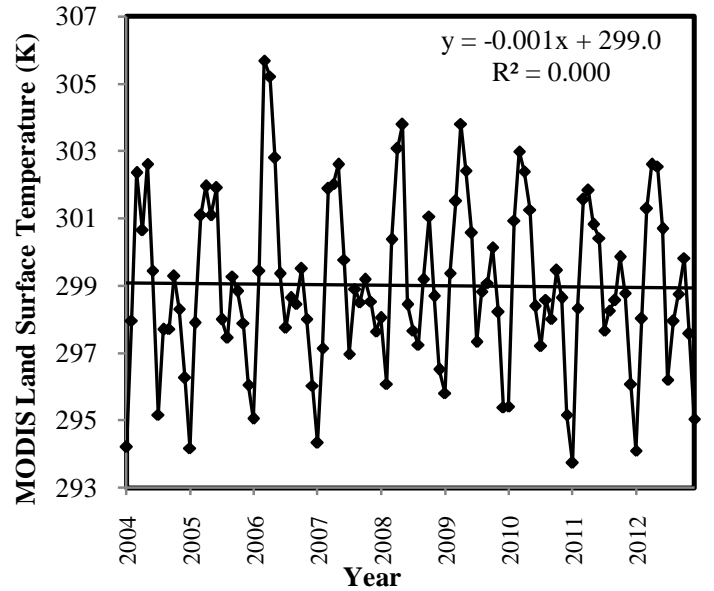

(b)

Fig 10. Area averaged time series and trends of (a) TRMM rain rate (2004-2013) and (b) MODIS land surface

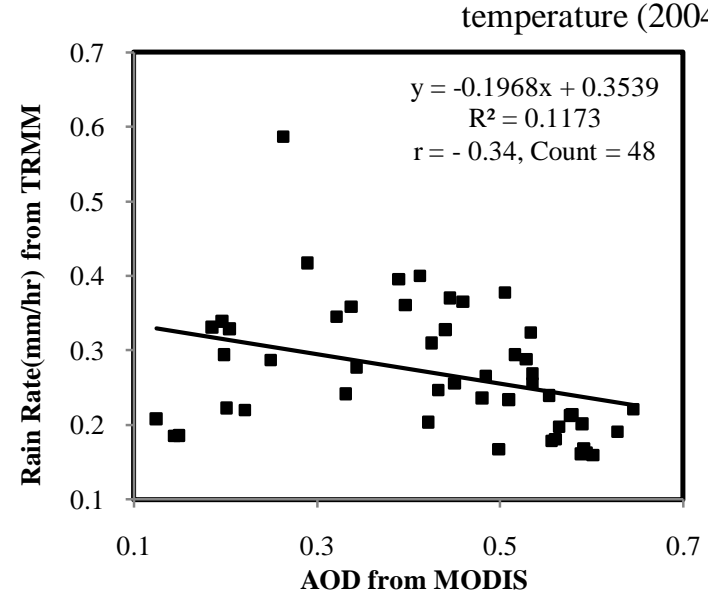

(a)

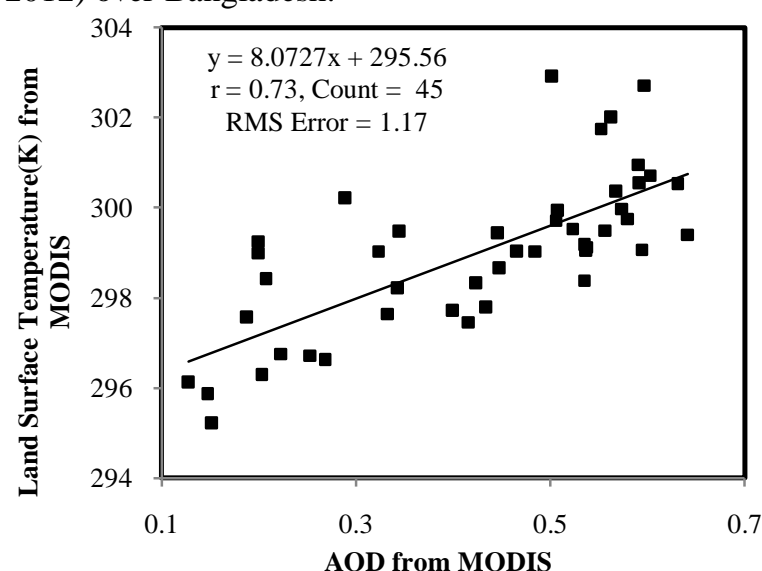

(b)

Fig 11. Correlation of time averaged monthly mean MODIS AOD with (a) TRMM rain rate (2004-2013) and (b) MODIS land surface temperature (2004-2012) over Bangladesh.

\section{Conclusion}

MODIS aerosol measurements are used to analyze the variability of aerosol optical properties over Bangladesh during the last decade. It is seen that aerosol concentrations are increasing with time. The increasing aerosol concentrations is being a result of the larger and increasing population, rapid urbanization, increased industrialization and the large pollution in Bangladesh. AOD and FMF trends are increasing across Bangladesh in the last decade while AE is decreasing. Therefore small or fine mode aerosol loading is increasing but higher diameter aerosol particle loading is decreasing over Bangladesh indicating anthropogenic activities are increasing. AOD, FMF and $\mathrm{AE}$ are exhibiting spatial, monthly, seasonal and annual mean variations over Bangladesh. Higher AODs with lower FMFs and AEs are found in western regions than the eastern regions. Higher temperature, lower rainfall, arid environment and pollutions from neighboring states of India are dominant and they are the reasons for higher aerosol concentrations. AOD shows strong negative correlation with AE than FMF over Bangladesh. Southeastern Chittagong division shows the highest negative correlations of AOD with AE and FMF. The monthly variations of aerosol properties are revealed that AOD peak occurs during June. FMF and AE are showing their peaks in October with minimum AOD. The smaller aerosol particles lead to a lower AOD. In post-monsoon lowest AOD with highest FMF and AE are observed. The season of highest AOD with lowest AE is pre-monsoon. In addition lowest FMF is occurred in monsoon season. Higher temperature, higher wind speed, higher humidity and sea salt particles blown from Bay of Bengal and Arabian Sea are the responsible causes of highest aerosol loading in pre-monsoon or summer season. On the other hand due to rain wash out process during post-monsoon the environment remains clean and anthropogenic activities also lower in this time which have a lower aerosol loading in post-monsoon season. AOD exhibits good relationships with TRMM rain rate and MODIS land surface temperature as the meteorological parameters. AOD has strong positive association with MODIS land surface temperature which indicates that 
higher land surface temperature increases the aerosol particles loading at atmosphere. On the other hand AOD and TRMM rain rate has negative correlation and the result suggests that higher rainfall reduces aerosol loading or higher AOD reduces rainfall and vice versa.

\section{Acknowledgements}

The authors are thankful to GES-MODIS and GES-TRMM for providing the satellite datasets.

\section{References}

[1]. Alam, K., Trautmann, T., Blaschke, T., 2011, Aerosol Optical Properties and radiative forcing over mega city Karachi. Journal of Atmospheric Research, doi: 10.1016/ j.atmosres.2011.05.007.

[2]. Alpert, P., Kaufman, Y.J., Shay-El, Y., Tanre, D., da Silva, A., Schubert, S., Joseph, J.H., 1998, Quantification of dust-forced heating of the lower atmosphere, Nature 395, 367-370.

[3]. Chu, D., Y. Kaufman, C. Ichoku, L. Remer, D. Tanré, and B. Holben, 2002, Validation of MODIS aerosol optical depth retrieval over land,Geophysical Research Letters, 29, 8007, doi:10.1029/2001/GL013205.

[4]. Chu, D.A., Kaufman, Y.J., Zibordi, G., Chern, J.D., Mao, J., Li, C., Holben, B.N., 2003, Global monitoring air pollution over land from the earth observing systemterra moderate resolution imaging spectroradiometer (MODIS), Journal of Geophysical Research 108, D21, doi:10.1029/2002JD003179.

[5]. El-Metwally, M., Alfaro, S.C., Abdel Wahab, M.M., Zakey, A.S., Chatenet, B., 2010, Seasonal and inter-annual variability of the aerosol content in Cairo (Egypt) as deduced from the comparison of MODIS aerosol retrievals with direct AERONET measurements, Atmos. Res. 97, 14-25.

[6]. Habib, G., Venkataraman, C., Chiapello, I., Ramachandran, S., Boucher, O., Reddy, M.S., 2006, Seasonal and interannual variability in absorbing aerosols over India derived from TOMS: relationship to regional meteorology and emissions, Atmospheric Environment, 40, 1909e1921.

[7]. Hansen, J., Sato, M., Ruedy, R., Lacis, A., Oinas, V., 2000, Global warming in the twenty-first century: an alternative scenario, Proc. Natl. Acad. Sci. U. S. A., 97, 9875-9880.

[8]. Intergovernmental Panel on Climate Change (IPCC), 2007, Climate Change: The Physical Science Basis, Cambridge University Press, New York, 131-216.

[9]. Islam, N. M., and Uyeda, H., 2007, Use of TRMM in determining the climatic characteristics of rainfall over Bangladesh, Remote Sens. Environ., 108(3), 264-276.

[10]. Javanmard, S., Yatagai, A., Nodzu, M.I., Bodaghjamali, J. and Kawamoto, H., 2010, Comparing High-resolution Gridded Precipitation Data with Satellite Rainfall Estimates of TRMM 3B42 over Iran, Adv. Geosci.,25, 119-125.

[11]. King, M.D., Kaufman, Y.J., Tanre, D., Nakajima, T., 1999,Remote sensing of tropospheric aerosols from space: past, present, and future, Bull. Am. Meteorol. Soc., 80, 2229-2259.

[12]. Park S, Panicker AS, Lee DI, Jung WS, Jang SM, Jang M, Kim YW, Kim DC, Kim Y, Jeong H., 2011, Characterization of aerosol chemical properties over Anmyeon (South Korea), a super site under Global Atmosphere Watch,Journal of Atmospheric Chemistry.

[13]. Kaskaoustis, D.G., Kambezidis, H.D., Hatzianastassiou, N., Kosmopoulos, P.G., Badarinath, V.S., 2007, Aerosol climatology: on the discrimination of aerosol types over four AERONET sites, Atmospheric Chemistry and Physics, 7, $6357 \mathrm{e} 6411$.

[14]. Kaufman, Y.J., Tanre, D., Remer, L.A., Vermote, E.F., Chu, A., Holben, B.N., 1997, Operational remote sensing of tropospheric aerosol over land from EOS moderate resolution imaging spectroradiometer, J. Geophys. Res., 102, 17,051-17,067.

[15]. Levy, R., L. Remer, S. Mattoo, E.Vermote, and Y. Kaufman, 2007b, Second-generation algorithm for retrieving aerosol properties over land from MODIS spectral reflectance,Journal of Geophysical Research, 112, D13211, doi:10.1029/2006JD007811.

[16]. Mamun, M. I., Islam, M., \& Mondol, P. K., 2014, The Seasonal Variability of Aerosol Optical Depth over Bangladesh Based on Satellite Data and HYSPLIT Model, American Journal of Remote Sensing, 2(4), 20-29,doi: 10.11648/j.ajrs.20140204.11.

[17]. Mondol, P. K., Mamun, M. M., Islam, M. M., 2014, Construction of an Inexpensive Sun Photometer to Measure Aerosol Optical Depth and Comparisons between the Measured Data and Satellite Observations, American Journal of Remote Sensing, 2(5), 37-43, doi:10.11648/j.ajrs.20140205.11.

[18]. Ramachandran, S., Jayaraman, A., Acharya, Y.B., Subbaraya, B.H., 1994, Features of aerosol optical depths over Ahmedabad as observed with a Sun-tracking photometer, Contributions to Atmospheric Physics, 67, 57e70.

[19]. Ramanathan, V., Crutzen, P.J., Kiehl, J.T., Rosenfeld, D., 2001, Aerosols, climate, and the hydrological cycle, Science, 294, 21192124.

[20]. Ramachandran, s., SumitaKedia, RohitSrivastava, 2012, Aerosol optical depth trends over different regions of India, Atmospheric Environment, 49, 338-347.

[21]. Rashid, H., 1991, Geography of Bangladesh,The University Press Limited, Dhaka, Bangladesh.

[22]. Remer, L., Y. Kaufman, D. Tanré, S. Mattoo, D. Chu, J. Martins, R. Li, C. Ichoku, R. Levy, R. Kleidman, T. Eck, E. Vermote, and B. Holben, 2005, The MODIS aerosol algorithm, products and validation, Journal of the Atmospheric Sciences, 62, 947-973.

[23]. Satheesh, S.K., Moorthy, K.K., Satheesh, S.K., Moorthy, K.K., 2005,Radiative effects of natural aerosols: a review, Atmos. Environ., 39 (11), 2089-2110.

[24]. Smart, J.C.R., Hicks, K., Morrissey, T., Heinemeyer, A., Sutton, M.A., Ashmore, M., 2011, Applying the ecosystem service concept to air quality management in the UK: a case study for ammonia,Environmetrics, 22, doi:10.1002/env.1094 n/a.

[25]. Tanre, D., Kaufman, Y.J., Herman, M., Mattoo, S., 1997, Remote sensing of aerosol properties over oceans using the MODIS/EOS spectral radiances, J. Geophys. Res., 102, 16,971-16,988.

[26]. Twomey, S.A., Piepgrass, M., Wolfe, T.L., 1984,An assessment of the impact ofpollution on the global albedo,Tellus 36B, 356366.

[27]. Wang, L.L., Wang, Y.S., Xin, J.Y., Li, Z.Q., Wang, X.Y., 2010, Assessment andcomparison of three years of Terra and Aqua MODIS aerosol optical depth retrieval (C005) in Chinese terrestrial regions, Atmos. Res., 97, 229-240.

[28]. Xueliang Deng, Chune Shi, Biwen Wu, Zhenghua Chen, SupingNie, Dongyan He, Hao Zhang, 2012, Analysis of aerosol characteristics and their relationships with meteorological parameters over Anhui province in China, Atmospheric Research, 109$110,52-56$. 